\title{
CDISC SDTM Discharge Disposition Terminology
}

National Cancer Institute

\section{Source}

National Cancer Institute. CDISC SDTM Discharge Disposition Terminology. NCI

Thesaurus. Code C101863.

Terminology associated with the discharge disposition codelist of the Clinical Data

Interchange Standards Consortium (CDISC) Study Data T abulation Model (SDT M). 